\title{
Structure and Hyperfine Interactions of Mechanically Activated Delafossite $\mathrm{CuFeO}_{2}$
}

\author{
K. Siedliska ${ }^{a}$, T. Pikula ${ }^{a}$, D. Oleszak ${ }^{b}$ And E. JARTyCh ${ }^{a, *}$ \\ ${ }^{a}$ Institute of Electronics and Information Technology, Lublin University of Technology, \\ ul. Nadbystrzycka 38a, 20-618 Lublin, Poland \\ ${ }^{b}$ Faculty of Materials Science and Engineering, Warsaw University of Technology, \\ ul. Wołoska 141, 02-507 Warsaw, Poland
}

\begin{abstract}
Delafossite $\mathrm{CuFeO}_{2}$ belongs to multiferroic class of materials. In this work, copper ferrite was prepared by mechanical activation with subsequent thermal treatment. X-ray diffraction and Mössbauer spectroscopy were used as complementary methods to study the structure and hyperfine interactions of the material. As proved by $\mathrm{X}$-ray diffraction, $\mathrm{CuFeO}_{2}$ compound was obtained with relatively low amount of secondary phases like $\mathrm{CuO}$ and $\mathrm{CuFe}_{2} \mathrm{O}_{4}$. The Mössbauer spectroscopy revealed paramagnetic character of the compound at room temperature. The purest delafossite $\mathrm{CuFeO}_{2}$ was obtained by mechanical activation of pre-milled precursors and sintering at $1173 \mathrm{~K}$. The temperature of thermal treatment is lower by $100 \mathrm{~K}$ as compared to the traditional solid-state synthesis.

DOI: 10.12693/APhysPolA.133.372

PACS/topics: 75.85.+t, 31.30.Gs, 76.80.+y
\end{abstract}

\section{Introduction}

Delafossites with $\mathrm{ABO}_{2}$ structure are relatively good recognized group of materials. They have specific applications as transparent semiconducting oxides, catalysts, luminescent materials, $p$-type semiconductors used in solar cells, etc., [1-3]. Many of delafossites are also multiferroics which increases the interest and efforts of researchers to find efficient methods of producing pure compounds. Delafossites have characteristic layered structure originally observed for the mineral $\mathrm{CuFeO}_{2}$ discovered in Siberia in 1873 [4]. One layer consists of the closepacked monovalent $\mathrm{Cu}$ ions and the other one is formed by edge-shared $\mathrm{Fe}^{3+} \mathrm{O}_{6}$ octahedra with iron cations inside $[5,6]$. The delafossite structure can form two polytypes depending on the orientation of layers in stacking, i.e., the rhombohedral $3 R$ type (space group $R-3 m$ ) and the hexagonal $2 H$ type (space group $P 6_{3} / m m c$ ) $[6,7]$.

Delafossite compounds are difficult to prepare without any special conditions. In the case of $\mathrm{CuFeO}_{2}$ this is connected with valence state of $\mathrm{Cu}$ ions, for which more favorable is the +2 state than +1 . Hence, the successful synthesis of copper ferrite requires strict control of the valence state. Another problem is when the reaction is carried out in air, which favorably leads to form $\mathrm{CuFe}_{2} \mathrm{O}_{4}$ compound with the spinel-type crystalline structure. If reaction of $\mathrm{Cu}_{2} \mathrm{O}$ and $\mathrm{Fe}_{2} \mathrm{O}_{3}$ is provided under nitrogen conditions, the pure copper delafossite phase is formed [8]. Until now, only high-temperature and ambient gas atmosphere methods have been developed for obtaining high quality samples. However, according to the recent report [9], it is possible using low-temperature

*corresponding author; e-mail: e.jartych@pollub.pl hydrothermal synthesis for preparation a pure $\mathrm{CuFeO}_{2}$ delafossite.

In the present work, another method is proposed for synthesis of $\mathrm{CuFeO}_{2}$ compound, namely mechanical activation (MA). In the MA technology, the mixture of the constituent oxides is placed into the vial of ball mill. However, the milling process itself is often not sufficient to produce the desired compound and requires additional thermal treatment [10-12]. The aim of this work was: (1) to synthesize $\mathrm{CuFeO}_{2}$ by MA technology and (2) to characterize the structure and hyperfine interactions of the compound after MA process as well as after heat treatment. X-ray diffraction (XRD) and Mössbauer spectroscopy (MS) were applied as complementary methods to study the structure and magnetic properties of the obtained delafossite.

\section{Experiment}

Two series of samples were synthesized by mechanical activation method and thermal treatment using $\mathrm{Fe}_{2} \mathrm{O}_{3}$ and $\mathrm{Cu}_{2} \mathrm{O}$ as constituent oxides (both purity $>99.9 \%$ ). A high-energy ball mill Fritsch Pulverisette P5 type with stainless steel balls of $10 \mathrm{~mm}$ diameter and 10:1 ball-topowder weight ratio was used. In the first series (MA I), oxides mixed in suitable proportions were milled in a nitrogen atmosphere for up to $50 \mathrm{~h}$. In the second one (MA II), oxides were firstly milled separately for $5 \mathrm{~h}$ in air, then mixed in the appropriate proportions and milled together in air for up to $50 \mathrm{~h}$. From both sets, the samples for measurements were picked after 2, 5, 10, 20 and $50 \mathrm{~h}$ of milling. The final products of MA I and MA II were heated from room temperature up to $993 \mathrm{~K}$ in a calorimeter Perkin Elmer DSC 7 under an argon atmosphere with a rate of $20 \mathrm{~K}$ per min. Another process of thermal treatment based on cold-pressing of final powder and pressureless sintering under a nitrogen for $10 \mathrm{~h}$ at $1173 \mathrm{~K}$. 
XRD measurements were performed using a Philips PW 1830 diffractometer working in a continuous scanning mode with $\mathrm{CuK}_{\alpha}$ radiation. X'Pert HighScore Plus computer program was used to phase analysis and determination of structural parameters. Room-temperature Mössbauer spectra were registered in a transmission geometry by means of a constant-acceleration POLON spectrometer of standard design. The $14.4 \mathrm{keV}$ gamma rays were provided by a source of ${ }^{57} \mathrm{Co}$ in a rhodium matrix. The spectrometer was calibrated using $\alpha$-Fe foil. The isomer shifts for all the samples were determined in relation to $\alpha$-Fe at room temperature.

\section{Results and discussion}

XRD and MS techniques allowed us to monitor the process of delafossite $\mathrm{CuFeO}_{2}$ formation. In the XRD patterns recorded after individual milling stages only systematic broadening of diffraction peaks may be observed (Fig. 1 presents the results for MA I series for example). Moreover, some peaks from $\mathrm{Cu}_{2} \mathrm{O}$ disappear while the main $\mathrm{Cu}_{2} \mathrm{O}$ peak (at $2 \Theta=36.5^{\circ}$ ) merges into one broad pile together with reflex from hematite.

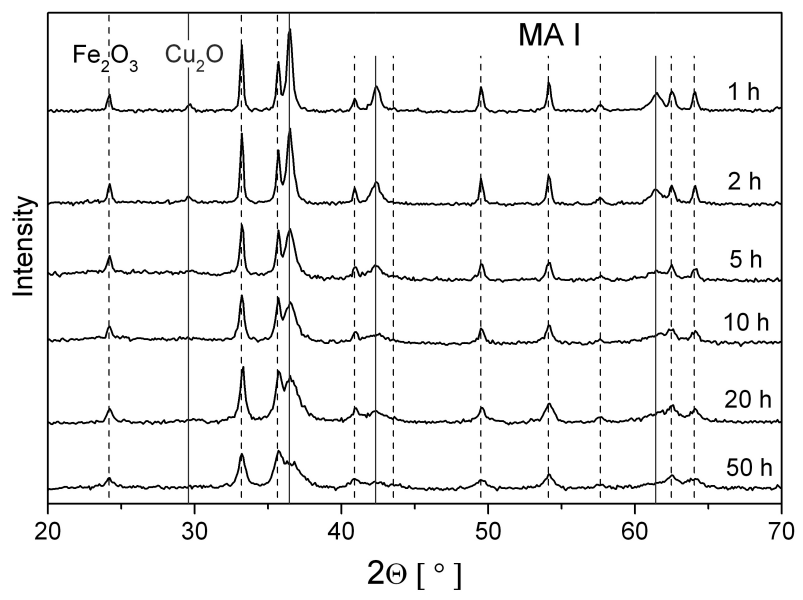

Fig. 1. XRD patterns recorded for MA I series after individual stages of milling process.

All Mössbauer spectra registered for the samples mechanically activated during $2-50 \mathrm{~h}$ consisted mainly of sextet originating from hematite and weak doublet in the central part of the spectrum (Fig. 2 presents the MS spectra for MA I series for example). Hyperfine interactions parameters of this doublet change with milling time slightly and for the samples milled for $50 \mathrm{~h}$ the values are as follows: isomer shift $\delta=0.35[\mathrm{~mm} / \mathrm{s}]$ for both MA I and MA II series and quadrupole splitting $\Delta=0.52[\mathrm{~mm} / \mathrm{s}]$ (MA I) and $0.62[\mathrm{~mm} / \mathrm{s}]$ (MA II). These parameters are similar to those reported for delafossite $\mathrm{CuFeO}_{2}(\delta=0.378[\mathrm{~mm} / \mathrm{s}]$ and $\Delta=0.619[\mathrm{~mm} / \mathrm{s}][13])$. Thus, the doublet in MS spectra may be treated as due to a new delafossite phase.

As shown, after mechanical activation for up to $50 \mathrm{~h}$ delafossite $\mathrm{CuFeO}_{2}$ phase may start to be formed; however,

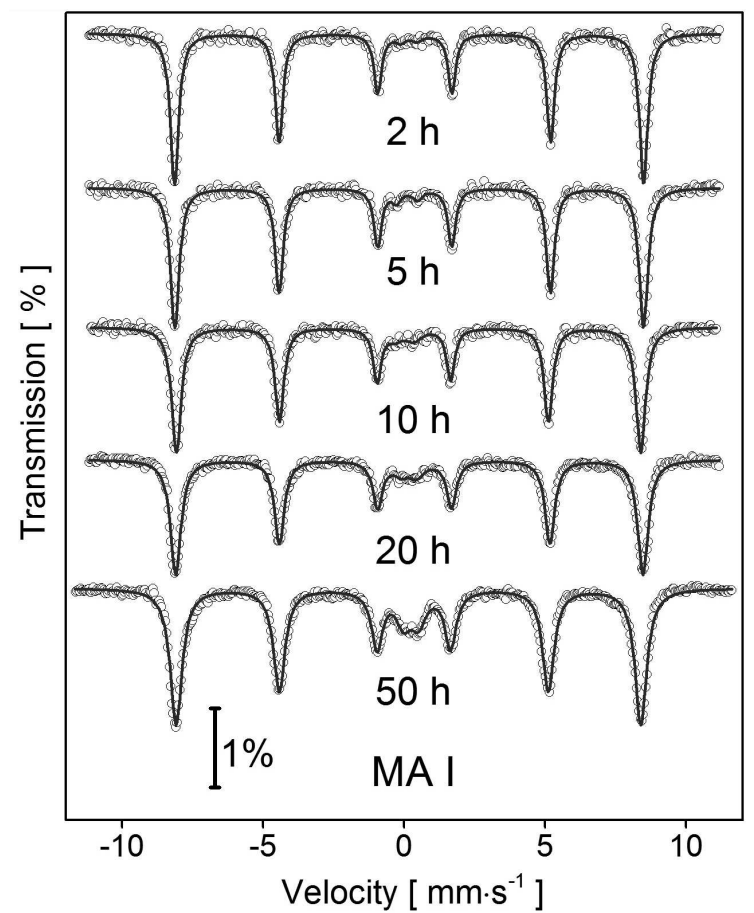

Fig. 2. Room-temperature MS spectra registered for MA I series after individual stages of milling process.

heat treatment is needed to complete the reaction. Fig. 3 presents comparison of XRD patterns for the samples after $50 \mathrm{~h} \mathrm{MA}$ and thermal treatment for both series. Already the process of gradual heating up to $993 \mathrm{~K}$ allowed the formation of delafossite; however, with some amount of non-reacted or new-formed oxides. After sintering at elevated temperature delafossite $\mathrm{CuFeO}_{2}$ is clearly visible as the main phase.

Analysis of XRD patterns was carried out under an assumption of rhombohedral lattice ( $R-3 m$ space group). The lattice parameters determined for the main $\mathrm{CuFeO}_{2}$ phase as well as its content $A$ estimated from the area of diffraction peaks are presented in Table I. The obtained values of $a$ and $c$ parameters are in good agreement with data published in [14].

Structural data for the main phase $\mathrm{CuFeO}_{2}$

TABLE I

\begin{tabular}{c|c|c|c}
\hline \hline \multicolumn{2}{c|}{ Series } & Lattice parameters $[\AA]$ & $\mathrm{A}[\%]$ \\
\hline \multirow{2}{*}{ MA I } & $50 \mathrm{~h}, 993 \mathrm{~K}$ & $a=3.040(2), c=17.19(2)$ & $\sim 70$ \\
& $50 \mathrm{~h}, 1173 \mathrm{~K}$ & $a=3.041(2), c=17.20(1)$ & $\sim 80$ \\
MA II & $50 \mathrm{~h}, 993 \mathrm{~K}$ & $a=3.036(1), c=17.18(1)$ & $\sim 40$ \\
& $50 \mathrm{~h}, 1173 \mathrm{~K}$ & $a=3.038(2), c=17.19(1)$ & $\sim 90$
\end{tabular}

Mössbauer spectra for the samples after MA process and thermal treatment are shown in Fig. 4. It may be noted that all the spectra are a superposition of sextet and doublet, excluding the spectrum for the sintered sample of MA II series. The doublet confirms that a paramagnetic $\mathrm{CuFeO}_{2}$ compound was formed during heat treatment. 

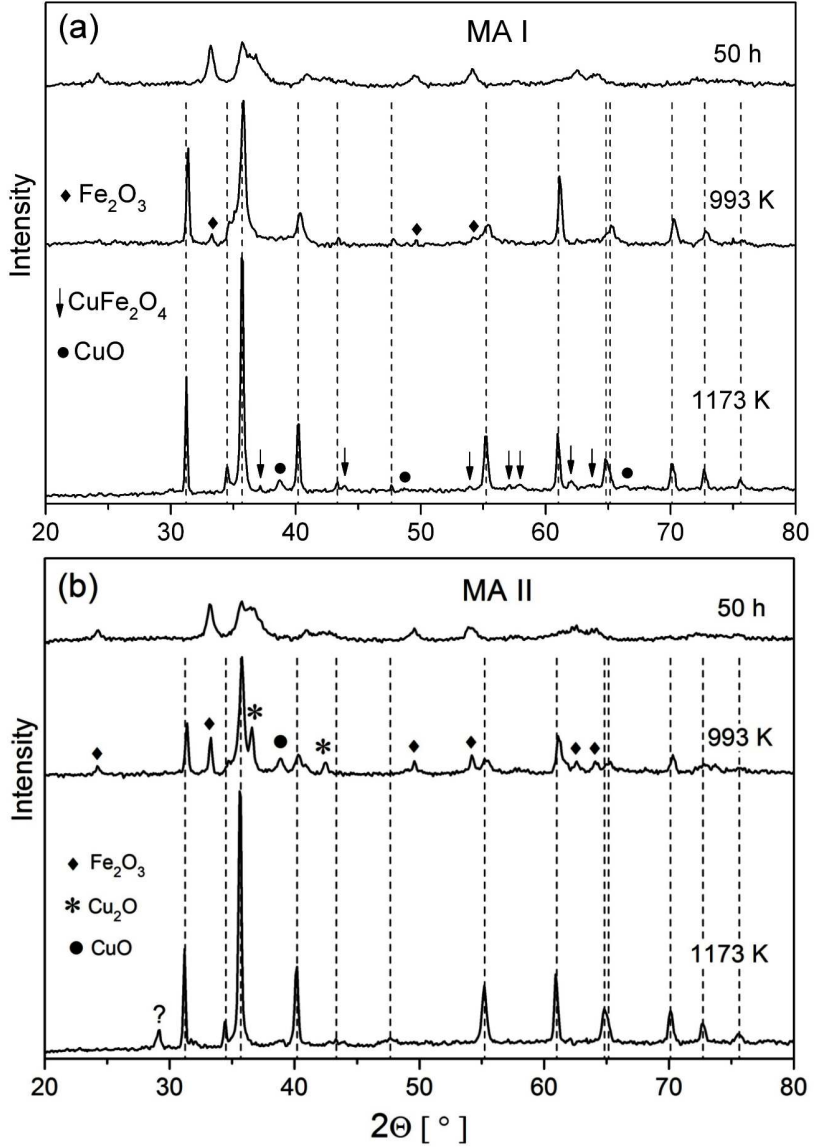

Fig. 3. XRD patterns for the samples after $50 \mathrm{~h}$ MA, heating up to $993 \mathrm{~K}$, and sintering at $1173 \mathrm{~K}$ : (a) MA I series, (b) MA II series (sign ? refers to unidentified phase; vertical lines are for $\mathrm{CuFeO}_{2}$ phase, PDF 00039-0246).

Hyperfine interactions parameters for the doublet determined by numerical fitting of the MS spectra are listed in Table II. The obtained values highly correspond with data reported for $\mathrm{CuFeO}_{2}$ delafossite obtained by solidstate reaction $[13,15]$ or hydrothermal synthesis [9]. The isomer shifts are typical of trivalent iron located in an octahedral site.

It may be added that the fuzzy sextet observed for the sintered sample of MA I series (Fig. 4a) was fitted by two components which have the values of hyperfine magnetic fields characteristic of spinel phase of $\mathrm{CuFe}_{2} \mathrm{O}_{4}$ $\left(B_{h f}=50.0\right.$ and $\left.47.1 \mathrm{~T}\right)$ [16]. This confirms results of phase analysis, when in XRD pattern (Fig. 3a) this compound was recognized as a secondary phase. However, this result is not consistent with literature data according to what spinel $\mathrm{CuFe}_{2} \mathrm{O}_{4}$ should not create during synthesis under nitrogen atmosphere.

\section{Conclusions}

It was shown that delafossite $\mathrm{CuFeO}_{2}$ may be prepared by mechanical activation with subsequent thermal treatment. Both XRD and MS techniques allowed monitoring

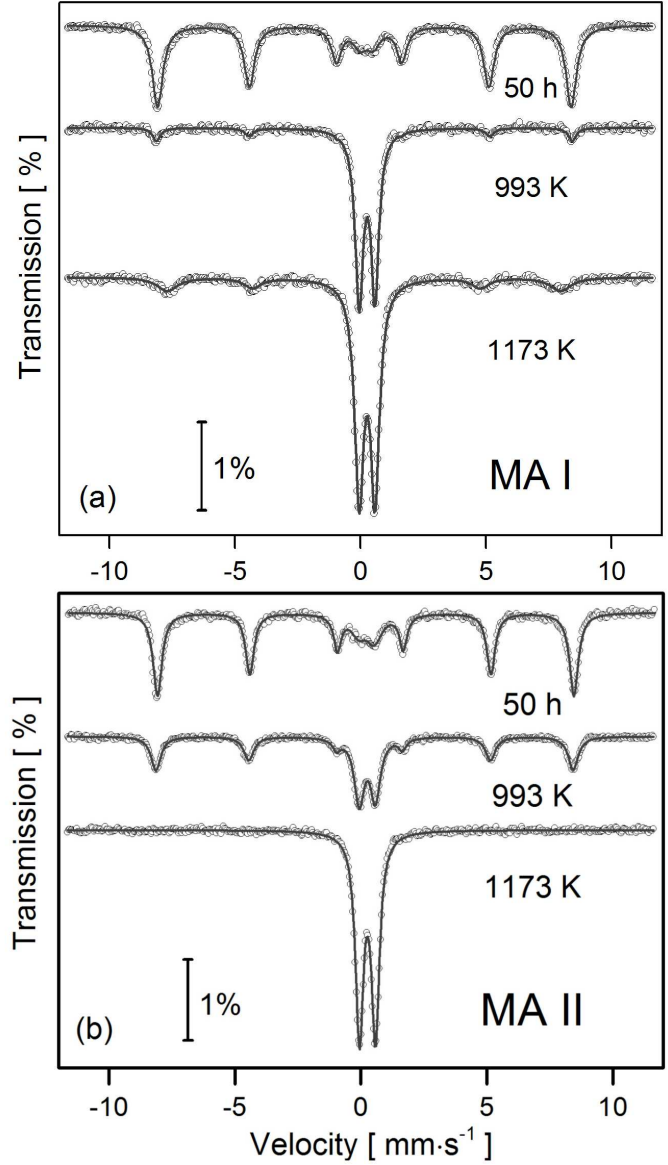

Fig. 4. Room-temperature MS spectra for the samples after mechanical activation, heating up to $993 \mathrm{~K}$, and sintering at $1173 \mathrm{~K}$ : (a) MA I series, (b) MA II series.

TABLE II

Hyperfine interactions parameters of $\mathrm{CuFeO}_{2}$ phase derived from Mössbauer spectra: $\delta$ - isomer shift relative to $\alpha$-Fe standard, $\Delta$ - quadrupole splitting; uncertainty for $\delta$ and $\Delta$ is $0.01[\mathrm{~mm} / \mathrm{s}]$.

\begin{tabular}{c|c|c|c|c}
\hline \hline \multicolumn{2}{c|}{ Series } & $\delta[\mathrm{mm} / \mathrm{s}]$ & $\Delta[\mathrm{mm} / \mathrm{s}]$ & Ref. \\
\hline \multirow{2}{*}{ MA I } & $50 \mathrm{~h}, 993 \mathrm{~K}$ & 0.36 & 0.62 & \\
& $50 \mathrm{~h}, 1173 \mathrm{~K}$ & 0.42 & 0.62 & this \\
MA II & $50 \mathrm{~h}, 993 \mathrm{~K}$ & 0.36 & 0.62 & work \\
& $50 \mathrm{~h}, 1173 \mathrm{~K}$ & 0.37 & 0.62 & \\
Solid-state & $1273 \mathrm{~K}$ & 0.378 & 0.619 & {$[13]$} \\
reaction & & 0.401 & 0.638 & {$[15]$} \\
Hydrother. & $343 \mathrm{~K}$ & 0.38 & 0.64 & {$[9]$} \\
synthesis & & & &
\end{tabular}

of technological process and obtaining the information about structure and magnetic properties of the material. The purest $\mathrm{CuFeO}_{2}$ phase was obtained by mechanical activation of preliminary milled precursors what may enhance the mutual diffusion of the component oxides. To complete solid state reaction and obtain pure delafossite $\mathrm{CuFeO}_{2}$ heat treatment is necessary; however, tempera- 
ture of sintering may be lower as compared with conventional technology. Improving the method of preparation and elimination of un-reacted oxides and/or secondary phases will be the subject of further research.

\section{References}

[1] A. Bera, K. Deb, K.K. Chattopadhyay, R. Thapa, B. Saha, Microelectron. Eng. 162, 23 (2016).

[2] M.S. Prévot, Y. Li, N. Guijarro, K. Sivula, J. Mater. Chem. A 4, 3018 (2016).

[3] Z. Deng, X. Fang, X. Wang, S. Wu, W. Dong, J. Shao, R. Tao, Thin Solid Films 589, 17 (2015).

[4] M.C. Friedel, C. R. Acad. Sci. Paris 77, 211 (1873).

[5] K.E. Farley, A.C. Marschilok, E.S Takeuchi, K.J. Takeuchi , Electrochem. Sol. St. 15(2), A23 (2012).

[6] M.M. Marquardt, N.A. Ashmore, D.P Cann, Thin Solid Films 496, 146 (2006).

[7] W.C. Sheets, E. Mugnier, A. Barnabé, T.J. Marks, K.R. Poeppelmeier, Chem. Mater. 18, 7 (2006).
[8] M. Lalanne, A. Barnabé, F. Mathieu, Ph. Tailhades, Inorg. Chem. 48, 6065 (2009).

[9] M. John, S. Heuss-Aßbichler, A. Ullrich, J. Solid State Chem. 234, 55 (2016).

[10] E. Jartych, B. Malesa, A. Antolak-Dudka, D. Oleszak, Acta Phys. Pol. A 125, 837 (2014).

[11] M. Mazurek, D. Oleszak, T. Pikula, M. Karolus, E. Jartych, Acta Phys. Pol. A 126, 975 (2014).

[12] T. Pikula, B. Malesa, D. Oleszak, M. Karolus, Z. Surowiec, V.I. Mitsiuk, E. Jartych, Solid State Commun. 246, 47 (2016)

[13] A. M. Sukeshini, H. Kobayashi, M. Tabuchi, H. Kageyama, Solid State Ionics 128, 33 (2000).

[14] R.D. Shannon, D.B. Rogers, C.T. Prewitt, Inorg. Chem. 10, 713 (1971)

[15] H. Wiederish, J.W. Savage, A.H. Muir Jr., D.G. Swarthout, Mineral. Magn. 36, 643 (1968).

[16] B.J. Evans, S. Hafner, G.M. Kalvius, Physics Letters 23, 24 (1966). 